\title{
Redução do peso e da glicemia resultante da suplementação de ácido linoleico conjugado e fitosteróis à dieta hiperlipídica de camundongos
}

\author{
Weight and blood glucose reduction resulting from conjugated linoleic acid and phytosterols \\ supplementation on hiperlipidic diets of mice
}

\author{
Anne y Castro Marques $^{\mathrm{I}}$ Nathalia Romanelli Vicente Dragano $^{\mathrm{I}}$ Mário Roberto Maróstica Júnior ${ }^{\mathrm{I}}$
}

\section{RESUMO}

O objetivo deste estudo foi avaliar as possíveis alterações causadas pela ingestão de ácido linoleico conjugado (CLA) e de fitosteróis no ganho de peso, na glicemia e no perfil lipídico de camundongos alimentados com dieta hiperlipídica. Durante nove semanas, vinte e cinco camundongos Swiss machos receberam dietas hiperlipídicas suplementadas com CLA e/ou fitosteróis, na concentração de $2 \%$. Foram aferidos consumo alimentar, ganho de peso, glicemia em jejum, além dos níveis séricos de colesterol total, triglicérides, HDL colesterol $e$ ácidos graxos livres. O grupo suplementado com CLA e fitosteróis apresentou menor ganho de peso e bom controle glicêmico, quando comparado aos demais grupos. Os resultados encontrados incentivam a continuação de pesquisas que investiguem os efeitos biológicos causados pela suplementação concomitante de CLA e fitosteróis, com possível aplicação na indústria de alimentos.

Palavras-chave: ácido linoleico conjugado, fitosteróis, perfil lipídico, glicemia.

\section{ABSTRACT}

The aim of this study was to evaluate the possible changes caused by conjugated linoleic acid (CLA) and phytosterols intake in weight gain, blood glucose levels and lipid profile on mice fed with high fat diet. Twenty-five male Swiss mice received for nine weeks high fat diets supplemented with $2 \%$ of CLA and/or phytosterols. Feed intake, weight gain, blood glucose, total cholesterol, triglycerides, HDL cholesterol and free fatty acids were determined. The group supplemented with CLA and phytosterols gained less weight and showed better glycemic control compared to other groups. The results encourage further research to investigate the biological effects caused by supplementation of CLA and phytosterols, with possible application in food industry.
Key words: conjugated linoleic acid, phytosterols, lipid profile, blood glucose.

\section{INTRODUÇÃO}

A informação de que a obesidade é um problema de saúde pública já se tornou senso comum. Entre as principais consequências dessa doença, que atinge milhões de pessoas no mundo, tem-se o desenvolvimento de dislipidemia, doenças cardiovasculares, osteoartrite, hérnias, diabetes, entre outros (COSTA, 2005). Diante da gravidade do quadro, inúmeras pesquisas têm apontado possíveis medicamentos, compostos e alimentos capazes de reduzir tanto a incidência quanto a prevalência da obesidade.

Entre os compostos oriundos dos alimentos, o ácido linoleico conjugado (CLA) vem recebendo destaque devido a sua ação reguladora do balanço energético e da composição corporal, reduzindo o ganho de peso e de massa gorda, além de aumentar massa magra (MOURÃO et al., 2005). OCLAé um grupo de ácidos graxos isômeros geométricos e de posição do ácido linoleico (C18:2 $\Delta 9 \mathrm{c}, 12 \mathrm{c} \mathrm{n}-6)$, sendo os isômeros 9c,11t e 10t,12c os mais estudados. A gordura e o leite de animais ruminantes são importantes fontes alimentares desse composto, o qual pode também ser produzido quimicamente a partir do ácido linoleico

IDepartamento de Alimentos e Nutrição, Faculdade de Engenharia de Alimentos, Universidade Estadual de Campinas (UNICAMP), Rua Monteiro Lobato, 80, Cidade Universitária Zeferino Vaz, 13083-862, Campinas, SP, Brasil. Email: annezita@gmail.com.

"Autor para correspondência. 
(GUNSTONE \& HERSLÖF, 2000; BANNI, 2002; COULTATE, 2002; SANTOS-ZAGO et al., 2008). Entretanto, apesar das atividades benéficas apontadas, o CLA também vem sendo investigado por seus efeitos biológicos adversos, como causar e/ou favorecer a resistência à insulina e atuar como pró-oxidante in vivo (WANG \& JONES, 2004; RISÉRUS et al., 2004; SIMÓN et al., 2006).

Outros compostos que vem recebendo a atenção de pesquisadores são os fitosteróis, substâncias análogas ao colesterol, presentes em plantas (BOBBIO \& BOBBIO, 2003). Os fitosteróis são amplamente encontrados na soja, oleaginosas e em óleos vegetais, e seu consumo tem sido relacionado positivamente à redução dos níveis de colesterol sérico e, consequentemente, ao menor risco de doenças cardiovasculares. A união de um fitosterol a um ácido graxo de cadeia longa aumenta a solubilidade dos esteróis em óleos e gorduras, sendo eficiente em doses muito baixas (COULTATE, 2002; MARTINS et al., 2004; ACÍN et al., 2007).

Pelo fato de serem substâncias com comprovado efeito biológico, é possível que a interação entre CLA e fitosteróis melhore e/ou potencialize seus efeitos, aumentando a absorção dos fitosteróis pelo organismo, atuando na composição corporal, regulando os níveis de lipoproteínas séricas e reduzindo a resistência à insulina (COULTATE, 2002; NTANIOS et al., 2003; JANSEN et al., 2006). O objetivo deste trabalho foi, portanto, avaliar as possíveis alterações causadas pela ingestão de CLA e de fitosteróis no ganho de peso, na glicemia e no perfil lipídico de camundongos alimentados com dieta hiperlipídica.

\section{MATERIAL E MÉTODOS}

Suplementos utilizados no estudo: foram utilizados óleo de cártamo (como fonte de ácido linoleico), mistura comercial de CLA Tonalin ${ }^{\circledR} \mathrm{e}$ fitosteróis Vegapure ${ }^{\circledR} 95 \mathrm{FF}$, todos produzidos pela Cognis Brasil Ltda.

Determinação do perfil de ácidos graxos: a análise do perfil de ácidos graxos dos suplementos foi realizada por cromatografia gasosa. As amostras foram metiladas e esterificadas segundo MAIA (1992), e as condições cromatográficas empregadas foram: cromatógrafo gasoso capilar CGC Agilent 6850 Series GC System equipado com coluna capilar DB-23 Agilent (50\% cianopropil) - metilpolisiloxano de dimensões $60 \mathrm{~m}$, Ø interno $0,25 \mathrm{~mm}, 0,25 \mu \mathrm{m}$ filme; fluxo de gás de arraste $(\mathrm{He})$ de $1,00 \mathrm{~mL} \mathrm{~min}^{-1}$; velocidade linear de $24 \mathrm{~cm}$ seg $^{-1}$; detector a $280^{\circ} \mathrm{C}$; injetor a $250^{\circ} \mathrm{C}$; forno a $110^{\circ} \mathrm{C}$ $5 \mathrm{~min}^{-1}, 110 / 215^{\circ} \mathrm{C}\left(5^{\circ} \mathrm{C} \mathrm{min}^{-1}\right), 215^{\circ} \mathrm{C} 34 \mathrm{~min}^{-1}$; volume injetado 1,0 L, split 1:50.
Análise dos fitosteróis: a análise dos fitosteróis foi realizada nos suplementos por cromatografia gasosa (BECKER et al., 2005). As amostras foram preparadas com solução de $\mathrm{KOH} 20 \%$ em metanol e diidrocolesterol (padrão interno), permanecendo em refluxo por duas horas. O óleo foi extraído três vezes, com posterior evaporação do solvente. Adicionou-se reagente de derivatização (BSTFA com 1\% TMCS) e piridina, com posterior aquecimento em estufa $\left(65^{\circ} \mathrm{C}\right.$ por uma hora). A identificação e a quantificação dos fitosteróis foi realizada em cromatógrafo a gás Agilent 6850 Series GC System, com injetor automático acoplado a detector FID, com software Agillent Chemstation Plus, version A.08xx, utilizando coluna capilar de sílica fundida LM 5 (5\% fenil $95 \%$ metilpolisiloxano, $30 \mathrm{~m}, 0,25 \mathrm{~mm}$ de diâmetro interno, $0,3 \mu \mathrm{m}$ de espessura de filme).

Dietas: para a realização do estudo in vivo, foi elaborada uma dieta padrão AIN 93-G (REEVES et al., 1993) com $12 \%$ de proteína (GOENA et al., 1989) (grupo P) e uma dieta AIN 93-G modificada, com aproximadamente $35 \%$ de lipídio (CINTRA, 2008) e 12\% de proteína (grupo HF). À dieta hiperlipídica foi adicionado CLA (grupo C), fitosteróis (grupo F) e CLA + fitosteróis (grupo CF). As dietas P e HF foram suplementadas com óleo de cártamo como controle. Todos os suplementos foram adicionados (sem substituição da banha e do óleo de soja) na concentração de $2 \%$ do composto de interesse em relação ao peso total da dieta, por ser a melhor doseresposta encontrada na literatura, tanto para o CLA quanto para os fitosteróis (NTANIOS et al., 2003; BOTELHO et al., 2005). Após a elaboração das dietas, foram determinadas as quantidades de umidade, proteína total, cinzas (AOAC, 1995) e lipídios (BLIGH \& DYER, 1959). O valor de carboidrato foi obtido por diferença e o valor energético das dietas foi determinado em calorímetro isoperibol automático (PARR 1261) com bomba de oxigênio (PARR 1108).

Animais: camundongos Swiss machos, recém desmamados, provenientes do Centro Multidisciplinar de Investigação Biológica da Unicamp (CEMIB), foram randomizados em cinco grupos $(\mathrm{n}=5)$, permanecendo sete dias em aclimatação e por oito semanas em experimento. Os animais foram mantidos em gaiolas individuais com água e alimentação sob o sistema de livre acesso, com temperatura ambiente e umidade do ar controlada $\left(22 \pm 1^{\circ} \mathrm{C}\right.$ e $60-70 \%$, respectivamente), e sob ciclo claro/escuro de 12 horas. A avaliação do consumo de dieta e a verificação do ganho de peso corporal foram feitas a cada dois dias e uma vez por semana, respectivamente. A glicemia foi aferida na sétima semana experimental, por meio de 
hemo-gluco-teste em aparelho Optium Mini (Abbott), com os animais em jejum de 6 horas. O sangue foi coletado da veia caudal e o resultado foi expresso em $\mathrm{mg} \mathrm{dL}^{-1}$. O sangue utilizado para as demais análises foi coletado ao final do período experimental sob anestesia (proporção de 1:1 de quetamina e diazepan, na concentração $5 \mathrm{mg} / \mathrm{kg}$ ), por meio de punção cardíaca e após jejum de 12 horas. As amostras foram armazenadas em tubos de polietileno $(1,5 \mathrm{~mL})$ e centrifugadas a 2.500rpm por 15 minutos, a $4^{\circ} \mathrm{C}$, para a separação do soro. Os níveis séricos de colesterol total (CT), triglicérides (TG) e lipoproteína de alta densidade (HDLc, high-density lipoprotein cholesterol) foram determinados por kits comerciais da marca Laborlab e os resultados foram expressos em $\mathrm{mg} \mathrm{dL}^{-1}$. A determinação de ácidos graxos livres (AGL) foi realizada por kit ELISA da marca Wako, e o resultado foi expresso em $\mathrm{mmol} \mathrm{L}^{-1}$.

Análise estatística: por meio do programa Statistical Analyses System 9.1.3 (SAS, 2003), os resultados foram submetidos à análise de variância (ANOVA) e as médias dos tratamentos foram comparadas pelo teste de Tukey $(\mathrm{P}<0,05)$.

\section{RESULTADOS E DISCUSSÃO}

A partir da análise da composição em ácidos graxos, verificou-se que a mistura comercial de CLA Tonalin $^{\circledR}$ é composta por $81,3 \%$ de isômeros C18:2 trans, sendo que os isômeros $9 \mathrm{c}, 11 \mathrm{t}$ e $10 \mathrm{t}, 12 \mathrm{c}$ representam $80,0 \%$ da composição do suplemento (na proporção $1: 1)$. O óleo de cártamo, por sua vez, apresentou 76,7\% de ácido linoleico (C18:2) em sua composição. Em relação à concentração de fitosteróis, o suplemento Vegapure ${ }^{\circledR}$ 95FF apresentou $54 \%$ de fitosteróis totais, sendo os fitosteróis majoritários $\beta$ sitosterol, campesterol e campestanol (47,3\%, 28,3\% e $13,4 \%$ do total de fitosteróis, respectivamente).

A formulação das dietas, assim como a composição centesimal delas, é apresentada na tabela 1 . Em relação à composição centesimal, as dietas foram semelhantes quanto às quantidades de proteína e de cinzas, variando em relação aos demais componentes e ao valor energético. Como não houve a substituição do óleo de soja pelo óleo de cártamo (usado como controle), a dieta padrão AIN 93-G apresentou teor de lipídio superior ao recomendado por REEVES et al. (1993).

Tabela 1 - Composição das dietas oferecidas aos camundongos.

\begin{tabular}{|c|c|c|c|c|c|}
\hline Ingrediente $^{1}$ & $\mathrm{P}$ & $\mathrm{HF}$ & $\mathrm{C}$ & $\mathrm{F}$ & $\mathrm{CF}$ \\
\hline Caseína & 147,6 & 140,4 & 140,6 & 139,0 & 135,7 \\
\hline Óleo de soja & 68,2 & 39,0 & 39,0 & 38,6 & 37,7 \\
\hline Banha suína & 0,0 & 319,3 & 319,7 & 315,9 & 308,6 \\
\hline Amido de milho & 417,2 & 238,6 & 238,9 & 236,1 & 230,6 \\
\hline Maltodextrina & 138,5 & 79,2 & 79,3 & 78,4 & 76,6 \\
\hline Sacarose & 105,1 & 60,1 & 60,2 & 59,5 & 58,1 \\
\hline Celulose microcristalina & 48,7 & 48,7 & 48,8 & 48,2 & 47,1 \\
\hline Mix mineral & 34,1 & 34,1 & 34,2 & 33,8 & 33,0 \\
\hline Mix vitamínico & 9,7 & 9,7 & 9,8 & 9,6 & 9,4 \\
\hline L-cistina & 2,9 & 2,9 & 2,9 & 2,9 & 2,8 \\
\hline Bitartarato de colina & 2,4 & 2,4 & 2,4 & 2,4 & 2,4 \\
\hline Tercbutilhidroquinona (TBHQ) & 0,014 & 0,014 & 0,014 & 0,014 & 0,014 \\
\hline Óleo de cártamo & 25,4 & 25,4 & 0,0 & 0,0 & 0,0 \\
\hline Suplemento de CLA & 0,0 & 0,0 & 24,0 & 0,0 & 23,2 \\
\hline Vegapure $^{\circledR} 95 \mathrm{FF}$ & 0,0 & 0,0 & 0,0 & 35,7 & 34,9 \\
\hline Umidade & $8,59 \pm 0,09$ & $5,14 \pm 1,07$ & $5,50 \pm 0,20$ & $4,76 \pm 0,14$ & $4,73 \pm 0,17$ \\
\hline Proteína $(\mathrm{g} \%)^{2}$ & $12,43 \pm 0,74$ & $12,19 \pm 0,36$ & $12,08 \pm 0,32$ & $12,26 \pm 0,55$ & $12,12 \pm 0,55$ \\
\hline Lipídio(g\%) & $8,39 \pm 0,39$ & $39,34 \pm 0,47$ & $39,72 \pm 0,50$ & $38,90 \pm 0,57$ & $43,29 \pm 0,42$ \\
\hline Cinzas & $2,52 \pm 0,05$ & $2,11 \pm 0,07$ & $2,15 \pm 0,16$ & $2,24 \pm 0,03$ & $2,10 \pm 0,01$ \\
\hline Carboidrato $(\mathrm{g} \%)^{3}$ & 68,07 & 41,22 & 40,55 & 41,84 & 37,76 \\
\hline Valor energético ${ }^{4}$ & $435,4 \pm 0,1$ & $601,8 \pm 1,4$ & $597,2 \pm 0,4$ & $600,2 \pm 2,2$ & $615,2 \pm 2,4$ \\
\hline
\end{tabular}

${ }^{1}$ Ingredientes expressos em $\mathrm{g} \mathrm{kg}^{-1}$ de ração. P: grupo com dieta padrão; HF: grupo com dieta hiperlipídica; C: grupo suplementado com CLA; F: grupo suplementado com fitosteróis; CF: grupo suplementado com CLA e fitosteróis. As análises de umidade, proteína, lipídio e cinzas foram realizadas em triplicata, sendo os resultados expressos em média \pm desvio padrão. ${ }^{2}$ Valor de conversão utilizado para o cálculo de proteína: $\mathrm{N}=6,25 .{ }^{3}$ Inclui o valor de fibra alimentar. ${ }^{4}$ Valor expresso em kcal $100 \mathrm{~g}^{-1}$ de dieta, obtido por calorimetria.

Ciência Rural, v.42, n.2, fev, 2012. 
Os dados referentes ao consumo total, ganho de peso, glicemia em jejum e perfil lipídico são apresentados na figura 1. Os grupos experimentais, apesar de não mostrarem diferença estatística no consumo energético (Figura 1A), apresentaram diferenças significativas em relação ao ganho de peso total. Observando-se a figura 1B, é expressiva a semelhança entre os grupos HF e F, sendo estes os
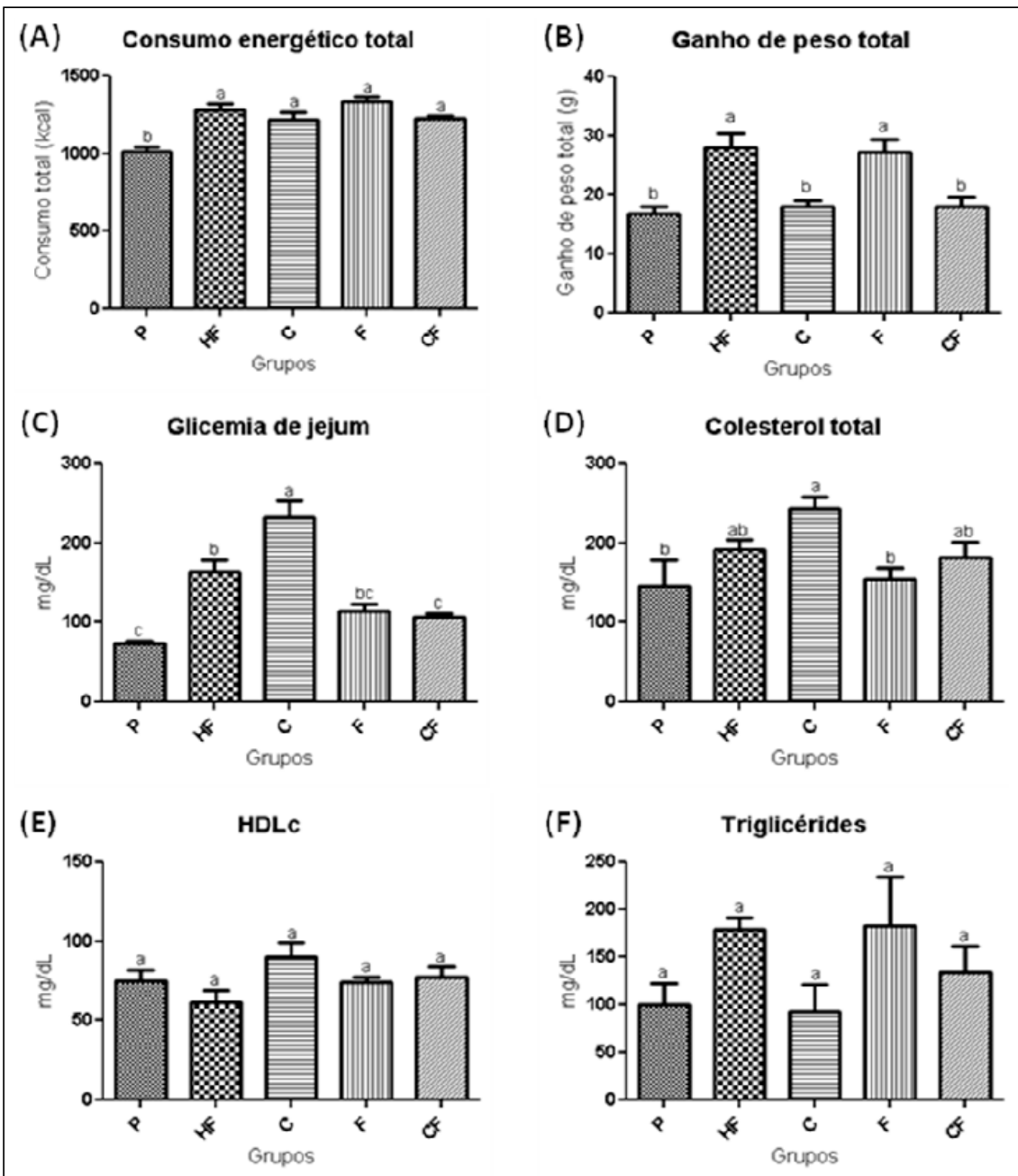

(G) Ácidos graxos livres

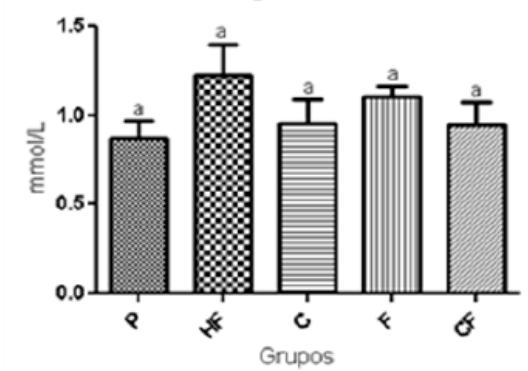

Figura 1 - Consumo energético total, ganho de peso total, glicemia de jejum e perfil lipídico sérico de camundongos suplementados com CLA e/ou fitosteróis. P: dieta padrão; HF: dieta hiperlipídica; C: grupo suplementado com CLA; F: grupo suplementado com fitosteróis; CF: grupo suplementado com CLA + fitosteróis. Sobrescritos diferentes no mesmo gráfico são estatisticamente diferentes, de acordo com o teste de Tukey $(\mathrm{P}<0,05)$. 
grupos com maior ganho de peso. Por outro lado, os grupos P, C e CF também foram semelhantes estatisticamente. Vale ressaltar que a redução do ganho de peso dos dois grupos suplementados com CLA foi numericamente inferior ao grupo $\mathrm{P}$, apesar de as dietas C e CF apresentarem mais de $35 \%$ de lipídio e a última ser normolipídica. Esse resultado nos permite afirmar que o CLA reduziu de forma expressiva o ganho de peso dos camundongos (-35,6\% para $\mathrm{C}$ e $-35,9 \%$ para $\mathrm{CF}$, quando comparados ao grupo $\mathrm{HF}$ ), enquanto os fitosteróis não alteraram o ganho de peso. Estudos realizados em seres humanos ainda não são conclusivos e as evidências sugerem que os diferentes isômeros do CLA possam apresentar efeitos variados na perda de peso. Em animais, já foi demonstrado que o isômero $10 \mathrm{t}, 12 \mathrm{c}$ é o que tem maior influência em modular a composição corporal (MOURÃO et al., 2005). Entre os possíveis mecanismos de ação do CLA para reduzir o ganho de peso estão a inibição do armazenamento de ácidos graxos (os quais são oxidados para fornecer energia), associado à inibição da entrada de glicose nos adipócitos. Apesar do efeito positivo causado no peso corporal, esses mecanismos podem também levar à alteração na via da insulina, causando hiperglicemia, hiperinsulinemia, resistência à insulina e diabetes (SANTOS-ZAGO et al., 2008; SO et al., 2009).

As informações descritas acima foram ratificadas nos resultados da glicemia em jejum (Figura 1C). A suplementação exclusiva com $2 \%$ de CLA causou alteração no metabolismo da glicose nos camundongos. O grupo $\mathrm{C}$ apresentou hiperglicemia severa, 42,2\% superior ao grupo HF. Em contrapartida, o grupo CF foi semelhante estatisticamente aos grupos $\mathrm{F}$ e $\mathrm{P}$, o que leva a considerar a hipótese de que a suplementação com fitosteróis levou a um efeito positivo no controle da glicemia. Segundo TANAKA et al. (2006), a administração de um gel de aloe vera, rica fonte de fitosteróis, preveniu o desenvolvimento de resistência à insulina e de intolerância à glicose em camundongos alimentados com dieta hiperlipídica. Apesar de não ser possível apontar qual(s) o(s) mecanismo(s) envolvido(s) no aumento da glicemia dos animais do grupo $\mathrm{C}$ a partir dos dados obtidos no presente experimento, a suplementação com ácido linoleico conjugado tem sido constantemente mencionada em estudos como indutor da resistência à insulina em animais e humanos (WANG \& JONES, 2004; SIMÓN et al., 2006; RISÉRUS et al., 2006). A insulina atua sobre o metabolismo de carboidratos, proteínas e lipídios, exercendo um efeito dominante na regulação da homeostase da glicose (COSTA, 2005). Outros estudos mostram, entretanto, resultados controversos aos mencionados anteriormente: PARRA et al. (2010) mostraram que uma mistura de isômeros de CLA não aumentou a resistência à insulina, quando suplementado oralmente em ratos; CHOI et al. (2004) observaram que ratos obesos suplementados com CLA apresentaram menor resistência à insulina quando comparados ao grupo controle; já HALADE et al. (2010) observaram, em camundongos C57B1/6J, um efeito antagônico dos diferentes isômeros de CLA: enquanto $\mathrm{o} 10 \mathrm{t}, 12 \mathrm{c}$ aumentou a resistência à insulina, o 9c,11t a reduziu. Pode-se dizer, portanto, que a relação do consumo de CLA e a sensibilidade à insulina ainda são controversos, não havendo um consenso sobre a real atuação do CLA e sobre os mecanismos de ação pelos quais ele atua. Da mesma forma, mais estudos são necessários para elucidar os mecanismos pelo qual os fitosteróis mantêm o controle glicêmico, mesmo na presença do ácido linoleico conjugado.

Com relação aos valores do colesterol sérico total (Figura 1D), o grupo C apresentou o maior valor médio e o grupo $\mathrm{F}$ o menor valor médio entre os grupos. O grupo CF, apesar de numericamente próximo ao grupo F, não diferiu estatisticamente do grupo HF. No estudo de NTANIOS et al. (2003), 130 hamsters adultos receberam, por doze semanas, dietas hiperlipídicas $(30 \%$ do valor energético), com $0,12 \%$ de colesterol e com diferentes quantidades de fitosteróis $(0,24 \%, 0,48 \%$, $0,96 \%, 1,92 \%$ e $2,84 \%)$. A eficácia da proteção à dieta hipercolesterolêmica, em relação ao colesterol total, foi encontrada em todas as dietas suplementadas com fitosteróis. Baseando-se nos resultados de outros grupos de pesquisa, era esperada, no presente estudo, uma diferença mais expressiva na redução do colesterol total causada pela suplementação com fitosteróis. Contudo, é importante salientar que diferenças como a idade dos animais, a composição das dietas, as condições experimentais e a espécie podem ocasionar resultados diferenciados.

As demais análises do perfil lipídico (HDLc, triglicérides e ácidos graxos livres) não mostraram diferença estatística entre os grupos (Figuras 1E, 1F e $1 \mathrm{G})$. O consumo diário de $2 \mathrm{~g}$ ou mais de fitosteróis tem mostrado, em estudos com pacientes hipercolesterolêmicos, reduzir entre 8 e $13 \%$ os níveis de colesterol séricos. Entretanto, os fitosteróis parecem não influenciar nos níveis plasmáticos de HDLc e de triglicérides (COULTATE, 2002; SOCIEDADE BRASILEIRA DE CARDIOLOGIA, 2007). Em relação aos ácidos graxos livres, especula-se que a inibição do armazenamento de ácidos graxos e glicose, especialmente pelo isômero CLA 10t,12c, leve ao acúmulo desses substratos na corrente sanguínea (SANTOS-ZAGO et al., 2008), o que não foi confirmado neste estudo. 


\section{CONCLUSÃO}

Com base nos resultados apresentados, é possível concluir que a suplementação concomitante de ácido linoleico conjugado e de fitosteróis apresentou efeitos biológicos benéficos no controle do ganho de peso e da glicemia em jejum, em camundongos recebendo dieta hiperlipídica. Estes achados incentivam a continuação de pesquisas que investiguem os efeitos sinérgicos de CLA e fitosteróis, com posterior desenvolvimento de nutracêuticos ou de alimentos funcionais.

\section{AGRADECIMENTOS}

Os autores agradecem à M. Cassab, pela doação do mix vitamínico, à Cognis Brasil Ltda, pela doação dos suplementos, assim como à Fundação de Amparo à Pesquisa do Estado de São Paulo (FAPESP) e ao Conselho Nacional de Desenvolvimento Científico e Tecnológico $(\mathrm{CNPq})$, pelo auxílio financeiro.

\section{COMITÊ DE ÉTICA}

Protocolo no 2019-1, em 19 de janeiro de 2010.

\section{REFERÊNCIAS}

ACÍN, S. et al. Olive oil preparation determines the atherosclerotic protection in apolipoprotein $\mathrm{E}$ knockout mice. Journal of Nutritional Biochemistry, v.18, p.418-424, 2007. Disponível em: <http://www.unav.es/preventiva/.../ J\%20Nutr\%20Biochem.\%202007-18-418-24.pdf>. Acesso em: 15 fev. 2011. doi:10.1016/j.jnutbio.2006.08.005.

AOAC. Official methods of analysis of AOAC. 16.ed CUNNIF, P. (Ed.). Virgínia, 1995. V.1.

BANNI, S. Conjugated linoleic acid metabolism. Current Opinion of Lipidology, v.13, p.261-266, 2002.

BECKER, D.F.S. et al. Quantificação de fitosteróis em azeite de oliva importados e disponíveis no comércio de Campinas utilizando cromatografia em fase gasosa. Brazilian Journal of Food Technology, v.8, n.3, p.190-199, 2005. Disponível em: <http:/ /www.grannutrille.com.br/arquivos/mod5/mod5_65.pdf>. Acesso em: 05 ago. 2009.

BLIGH, E.G.; DYER, W.J. A rapid method of total lipid extration and purification. Canadian Journal of Biochemistry and Phisiology, v.37, p.911-917, 1959.

BOBBIO, F.O.; BOBBIO, P.A. Introdução à química de alimentos. 3.ed. São Paulo: Varela, 2003. 238p.

BOTELHO, A.P. et al. A suplementação com ácido linoleico conjugado reduziu a gordura corporal em ratos Wistar. Revista de Nutrição, v.18, n.4, p.561-565, 2005. Disponível em: $<\mathrm{http}: / /$ www.scielo.br/scielo.php?pid=S 1415 . $52732005000400011 \&$ script $=$ sci arttext $>$. Acesso em: 03 mar. 2009. doi: $10.1590 / \mathrm{S} 1415-52 \overline{7} 32005000400011$.

CHOI, J.S. et al. Effect of conjugated linoleic acid isomers on insulin resistance and mRNA levels of genes regulating energy metabolism in high-fat-fed rats. Nutrition, v.20, p.10081017, 2004. Disponível em: <http://www.ncbi.nlm.nih.gov/ pubmed/15561492>. Acesso em: 25 out. 2009. doi: 10.1016/ j.nut.2004.08.009.

CINTRA, D.E.C. Integração entre vias metabólicas e inflamatórias durante a esteatose hepática induzida por dieta hiperlipídica. 2008. 100f. Tese (Doutorado em Clínica Médica) - Curso de Pós-graduação em Clínica Médica, Universidade Estadual de Campinas, SP.

COSTA, E.A. Manual de fisiopatologia e nutrição. Petrópolis: Vozes, 2005. 223p.

COULTATE, T.P. Food: the chemistry of its components. 4.ed. Cambridge: Royal Society of Chemistry, 2002. 432p.

GOENA, M. et al. Effect of the raw legume Vicia ervilha on muscle and liver protein metabolism in growing rats. Revista Española de Fisiologia, v.45, p.55-60, 1989.

GUNSTONE, F.D.; HERSLÖF, B.G. Lipid glossary 2. Bridgwater, England: The Oily, 2000. 250p.

HALADE, G.V. et al. Differential effects of conjugated linoleic acid isomers in insulin-resistant female C57B1/6J mice. Journal of Nutritional Biochemistry, v.21, n.4, p.332337,2010

JANSEN, P.J. et al. Dietary plant sterols accumulate in the brain. Biochimica et Biophysica Acta, v.1761, p.445-453, 2006. Disponível em: $<$ http://www.sciencedirect.com>. Acesso em: 17 fev. 2011. doi: 10.1016/j.bbalip.2006.03.015.

MAIA, E.L. Otimização de metodologia para caracterização de constituintes lipídicos e determinação da composição em ácidos graxos e aminoácidos de peixes de água doce. 1992. 242f. Tese (Doutorado em Tecnologia de Alimentos) - Curso de Pós-graduação em Tecnologia de Alimentos, Universidade Estadual de Campinas, SP.

MARTINS, S.L.C. et al. Efeitos terapêuticos dos fitosteróis e fitostanóis na colesterolemia. ALAN, v.54, n.3, p.257-263, 2004. Disponível em: <http://www.alanrevista.org/ediciones/ 2004-3/efeitos_terapeuticos_fitosterois_fitostanois.asp $>$. Acesso em: 04 ago. 2009.

MOURÃO, D.M. et al. Ácido linoleico conjugado e perda de peso. Revista de Nutrição, v.18, n.3, p.391-399, 2005. Disponível em: <http://www.scielo.br/scielo.php?pid=S141552732005000300011\&script $=$ sci_arttext $>$. Acesso em: 07 mar. 2009. doi: $10.1590 / \mathrm{S} 1415-52732005000300011$.

NTANIOS, F.Y. et al. Effects of various amounts of dietary plant sterol esters on plasma and hepatic sterol concentration and aortic foam cell formation of cholesterol-fed hamsters. Atherosclerosis, v.169, p.41-50, 2003. Disponível em: <http:/ /www.sciencedirect.com>. Acesso em: 19 set. 2009. doi: 10.1016/ S0021-9150(03)00132-1.

PARRA, P. et al. Moderate doses of conjugated linoleic acid isomers mix contribute to lowering body fat content maintaining insulin sensitivity and a noninflammatory pattern in adipose tissue in mice. Journal of Nutritional Biochemistry, v.21, n.2, p.107-115, 2010. Disponível em: <http://www.sciencedirect.com>. Acesso em: 17 fev. 2011. doi: 10.1016/j.jnutbio.2008.10.010. 
REEVES, P.G. et al. AIN-93 Purified diets for laboratory rodents: final report of the American Institute of Nutrition Ad Hoc Writing Committee on the Reformulation of the AIN-76A rodent diet. Journal of Nutrition, v.123, p.1939-1951, 1993.

RISÉRUS, U. et al. Metabolic effects of conjugated linoleic acid in humans: the Swedish experience. American Journal of Clinical Nutrition, v.79, p.1146S-1148S, 2004. Disponível em: <http://www.ajcn.org/content/79/6/1146S.full>. Acesso em: 12 abr. 2010.

SAS Institute. SAS 9.1.3 service pack3. Cary, 2003. 1 CD.

SANTOS-ZAGO, L.F et al. Os efeitos do ácido linoleico conjugado no metabolismo animal: avanço das pesquisas e perspectivas para o futuro. Revista de Nutrição, v.21, n.2, p.195-221, 2008. Disponível em: <http://www.scielo.br/scielo.php?pid=S141552732008000200008\&script $=$ sci_arttext $>$. Acesso em: $25 \mathrm{fev}$. 2009. doi: $10.1590 / \mathrm{S} 1415-52732008000200008$.

SIMÓN, E. et al. Trans-10, cis-12 conjugated linoleic acid prevents adiposity but not insulin resistance induced by an atherogenic diet in hamsters. Journal of Nutritional Biochemistry, v.17, p.126-131, 2006. Disponível em: <http:/ /www.sciencedirect.com>. Acesso em: 22 ago. 2010. doi: 10.1016/j.jnutbio.2005.06.001.
SO, M.H.H. et al. Dietary fat concentration influences the effects of trans-10, cis-12 conjugated linoleic acid on temporal patterns of energy intake and hypothalamic expression of appetite-controlling genes in mice. Journal of Nutrition, v.139, p.145-151, 2009. Disponível em: <http:// jn.nutrition.org/content/139/1/145.full>. Acesso em: 22 out. 2010. doi: $10.3945 /$ jn. 108.093849 .

SOCIEDADE BRASILEIRA DE CARDIOLOGIA. IV diretriz brasileira sobre dislipidemias e prevenção da aterosclerose. Arquivos brasileiros de cardiologia, v.88, Supl.I, 1-19p., 2007. Disponível em: <http://publicacoes.cardiol.br/consenso/ 2007/diretriz-DA.pdf>. Acesso em: 15 fev. 2011.

TANAKA, M. et al. Identi?cation of five phytosterols from aloe vera gel as anti-diabetic compounds. Biological \& Pharmaceutical Bulletin, v.29, n.7, p.1418-1422, 2006. Disponível em: <http:// bpb.pharm.or.jp/bpb/200607/b07_1418.pdf>. Acesso em: 21 fev. 2011 .

WANG, Y.W.; JONES, P.J.H. Conjugated linoleic acid and obesity control: efficacy and mechanisms. International Journal of Obesity, v.28, p.941-955, 2004. Disponível em: <http:// www.ncbi.nlm.nih.gov/pubmed/15254484>. Acesso em: 15 fev. 2011 . 